\title{
Serum Potassium Disorders Predict Subsequent Kidney Injury: A Retrospective Observational Cohort Study of Hospitalized Patients
}

\author{
Gianmarco Lombardi $^{a}$ Giovanni Gambaro ${ }^{a}$ Pietro Manuel Ferrarob, c

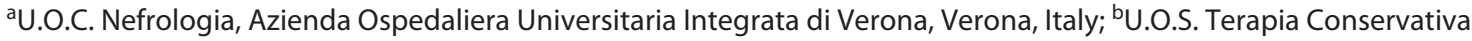 \\ della Malattia Renale Cronica, Dipartimento di Scienze Mediche e Chirurgiche, Fondazione Policlinico Universitario \\ A. Gemelli IRCCS, Roma, Italy; ' Dipartimento Universitario di Medicina e Chirurgia Traslazionale, Università Cattolica \\ del Sacro Cuore, Roma, Italy
}

\section{Keywords}

Acute kidney injury - Electrolyte disorders · Hypokalemia .

Hyperkalemia · Epidemiological study

\begin{abstract}
Introduction: Electrolyte disorders are common findings in kidney diseases and might represent a useful biomarker preceding kidney injury. Serum potassium $\left[\mathrm{K}^{+}\right]$imbalance is still poorly investigated for association with acute kidney injury (AKI), and most evidence came from intensive care units. The aim of our study was to comprehensively investigate this association in a large, unselected cohort of hospitalized patients. Methods: We performed a retrospective observational cohort study on the inpatient population admitted to Fondazione Policlinico Universitario A. Gemelli IRCCS between January 1, 2010 and December 31, 2014, with inclusion of adult patients with at least $2\left[\mathrm{~K}^{+}\right]$and 3 serum creatinine measurements who did not develop AKI during an initial 10day window. The outcome of interest was in-hospital AKI. The exposures of interest were $\left[\mathrm{K}^{+}\right]$fluctuations and hypo (HoK) and hyperkalemia (HerK). $\left[\mathrm{K}^{+}\right]$variability was evaluated using the coefficient of variation. Cox proportional hazards regression models were used to obtain hazard ratios and
\end{abstract}

Karger@karger.com www.karger.com/kbr

Karger ${ }^{\prime \prime} \div$

GOPEN ACCESS
C 2022 The Author(s).

Published by S. Karger AG, Basel

This is an Open Access article licensed under the Creative Commons Attribution-NonCommercial-4.0 International License (CC BY-NC) (http://www.karger.com/Services/OpenAccessLicense), applicable to the online version of the article only. Usage and distribution for commercial purposes requires written permission.
95\% confidence intervals of the association between the exposures of interest and development of AKI. Results: About 21,830 hospital admissions from 18,836 patients were included in our study. During a median follow-up of 5 (interquartile range [IQR] 7) days, AKI was observed in 555 hospital admissions (2.9\%); median time for AKI development was 5 (IQR 7) days. Higher $\left[\mathrm{K}^{+}\right]$variability was independently associated with increased risk of AKI with a statistically significant linear trend across groups ( $p$ value $=0.012$ ). A significantly higher incidence of AKI was documented in patients with HerK compared with normokalemia. No statistically significant difference was observed between HoK and HerK ( $p$ val$\mathrm{ue}=0.92$ ). Conclusion: $\left[\mathrm{K}^{+}\right]$abnormalities including fluctuations even within the normal range are associated with development of AKI.

(c) 2022 The Author(s)

Published by S. Karger AG, Basel

\section{Introduction}

Acute kidney injury (AKI) is a severe pathological condition often observed in the hospitalized population [ 1 , 2]. The reported incidence is quite variable, ranging from $7 \%$ to $57 \%[3,4]$. Higher morbidity and mortality associ- 


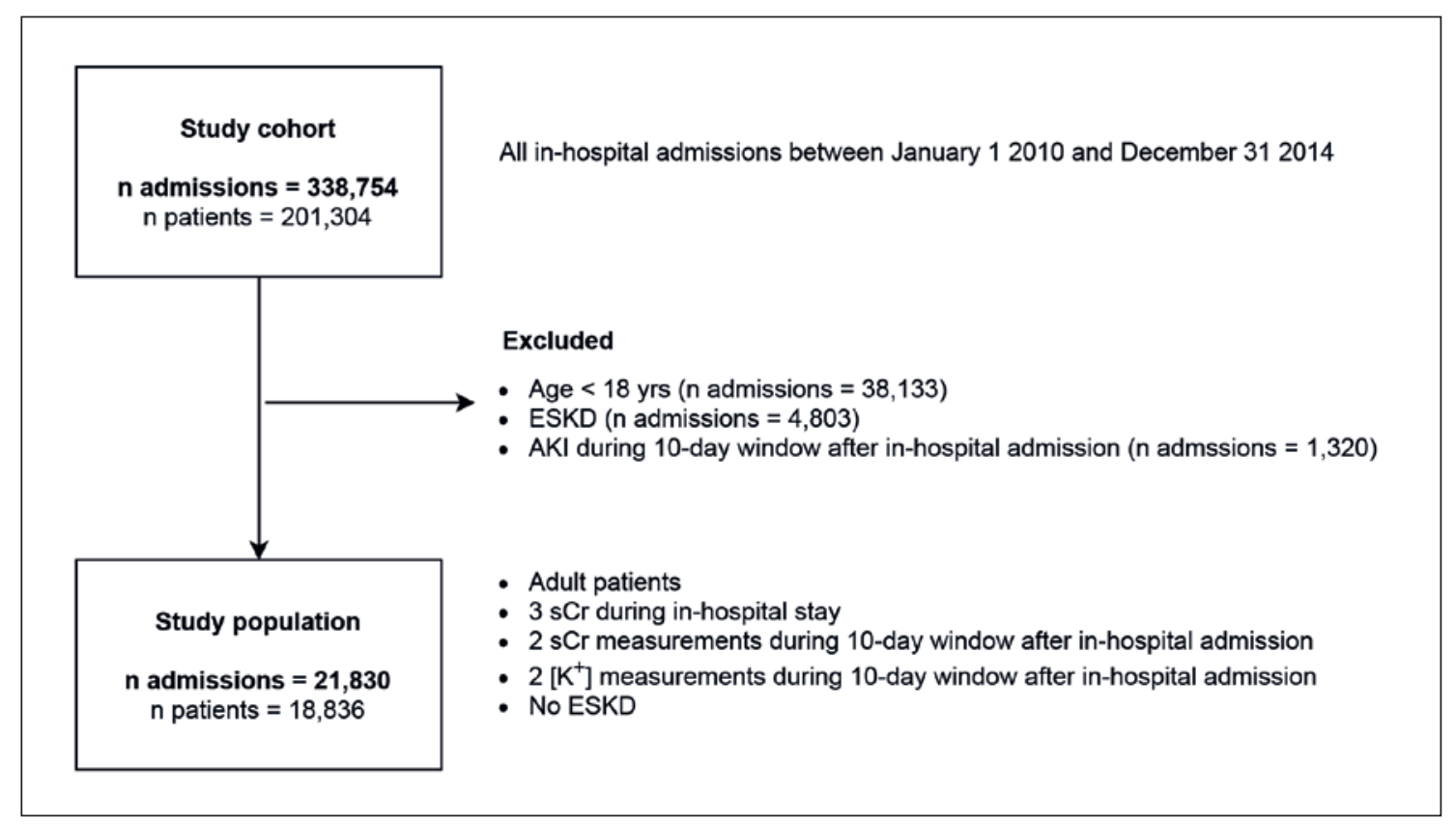

Fig. 1. Flowchart of the study.

ated with such a severe disease justify medical and scientific interest [5]. AKI is strongly associated with increased short-term (more than 4-fold increased likelihood of death in some reports [5]) and long-term mortality (mortality risk ranging from $40 \%$ to $60 \%$ [6]), higher risk of incident chronic kidney disease (CKD) or progression of preexisting CKD [7] as well as increased hospital resource utilization with a significant burden on the healthcare systems [8].

Since the kidney is the main organ involved in the homeostasis of water and electrolytes, it is not surprising that electrolyte disturbances have been frequently observed in AKI patients $[9,10]$. However, the few studies focusing on the electrolyte imbalances preceding kidney injury [11-14] reported a significant association between electrolyte disorders and AKI $[11,12,14]$. The electrolyte alterations associated with AKI were often described as simple bystanders that accompany other pathological conditions $[9,10]$, although a direct and independent causal association with kidney injury might be hypothesized $[11,12,14]$. Embracing this point of view, electrolyte disorders might represent a useful biomarker preceding overt kidney damage and potentially improving timely medical intervention.

Serum potassium $\left[\mathrm{K}^{+}\right]$disorders preceding AKI are still poorly investigated in the medical literature. To date, no works have comprehensively explored the relation- ship between $\left[\mathrm{K}^{+}\right]$imbalance and kidney injury or have explored its direct association with kidney damage. In order to provide new insights on such topic, we performed an observational study on a large cohort of hospitalized patients aimed at investigating the relationship between $\left[\mathrm{K}^{+}\right]$disorders (including $\left[\mathrm{K}^{+}\right]$variability, hyperkalemia $[\mathrm{HerK}]$, and hypokalemia $[\mathrm{HoK}])$ and AKI.

\section{Materials and Methods}

\section{Setting and Study Population}

We performed a retrospective observational cohort study on the inpatient population admitted to the Fondazione Policlinico Universitario Agostino Gemelli IRCCS between January 01, 2010 and December 31,2014 . We included only adult patients $(\geq 18$ years) with at least $2\left[\mathrm{~K}^{+}\right]$and 3 serum creatinine (sCr) measurements during the study period (Fig. 1). At least $2\left[\mathrm{~K}^{+}\right]$and $2 \mathrm{sCr}$ measurements during a 10-day window starting at in-hospital admission were considered necessary in order to explore the relationship between $\left[\mathrm{K}^{+}\right]$variability and AKI (Fig. 2). All patients developing AKI during the 10-day window were excluded, as well as patients with end-stage kidney disease.

\section{Data Collection}

Demographic, clinical, and laboratory data were collected for each patient: age, sex $\left[\mathrm{K}^{+}\right]$, sCr, primary and secondary International Classification of Disease, 9th Revision, Clinical Modification (ICD-9-CM) diagnostic codes at hospital discharge, and vital status at hospital discharge. The same flame photometer was used for $\left[\mathrm{K}^{+}\right]$measurements during the whole study period (normal 


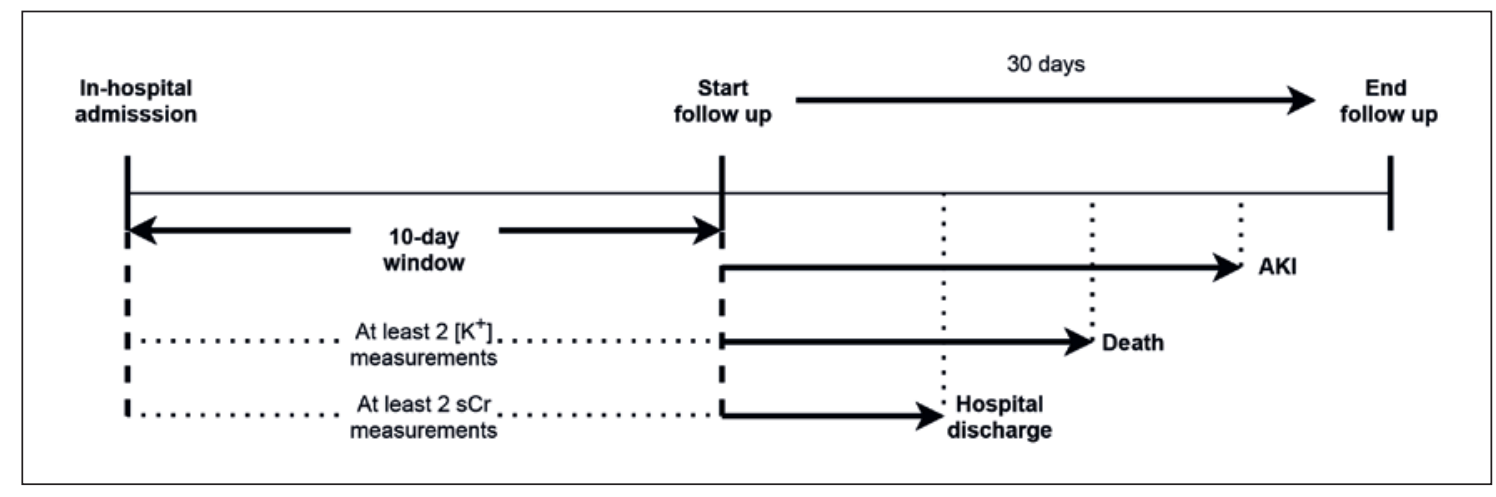

Fig. 2. Study design.

$\left[\mathrm{K}^{+}\right]$laboratory range $3.0-5.0 \mathrm{mmol} / \mathrm{L}$; analytical coefficient of variation $(\mathrm{CV})$ below $2.3 \%$ [range $1.3-1.7 \%]$ ). Extreme $\left[\mathrm{K}^{+}\right]$levels $(<2.0 \mathrm{mmol} / \mathrm{L}$ and $>7.5 \mathrm{mmol} / \mathrm{L})$, that could introduce distortion in the analyses and reflect untrue values (e.g., due to hemolysis), were removed.

\section{Definitions}

The CV was used as the measure of $\left[\mathrm{K}^{+}\right]$variability. Creatinine kinetics criteria were used for AKI definition [15]. The presence of AKI was assessed using absolute increases of sCr concentration during hospitalization. To do this, we calculated the difference between each sCr and the previously measured value during hospitalization. According to creatinine kinetics criteria, we defined $\mathrm{AKI}$ as an absolute increase in sCr of $\geq 0.3 \mathrm{mg} / \mathrm{dL}$ over $24 \mathrm{~h}$ or $\geq 0.5$ $\mathrm{mg} / \mathrm{dL}$ over $48 \mathrm{~h}$ observed after the initial 10 days [15].

Patients were categorized according to all $\left[\mathrm{K}^{+}\right]$values recorded during hospital stay in the following groups: $\mathrm{HoK}$ (any $\left[\mathrm{K}^{+}\right]$value $<3.0 \mathrm{mmol} / \mathrm{L}$ ), HerK (any $\left[\mathrm{K}^{+}\right]$value $>5.0 \mathrm{mmol} / \mathrm{L}$ ), and normokalemia $\left(\mathrm{NK}\right.$, all $\left[\mathrm{K}^{+}\right]$values $\geq 3.0 \mathrm{mmol} / \mathrm{L}$ and $\left.\leq 5.0 \mathrm{mmol} / \mathrm{L}\right)$. $\mathrm{Pa}-$ tients with a mixed $\left[\mathrm{K}^{+}\right]$disorder (lowest $\left[\mathrm{K}^{+}\right]$value $<3.0 \mathrm{mmol} / \mathrm{L}$ and highest $\left[\mathrm{K}^{+}\right]>5.0 \mathrm{mmol} / \mathrm{L}$ ) were classified as HoK or HerK, whichever occurred first.

Comorbid conditions (cardiovascular diseases, malignancies, gastrointestinal diseases, genitourinary disorders, endocrine/metabolic disorders, infectious, and respiratory diseases) were identified using ICD-9-CM codes. End-stage kidney disease was identified using ICD-9-CM diagnostic and procedural codes or laboratory data (baseline estimated glomerular filtration rate $[\mathrm{eGFR}]<15$ $\left.\mathrm{mL} / \mathrm{min} / 1.73 \mathrm{~m}^{2}\right)$ [14].

\section{Outcomes and Exposures}

In-hospital AKI was the main outcome of interest. $\left[\mathrm{K}^{+}\right]$variability, expressed as quartiles of $\left[\mathrm{K}^{+}\right] \mathrm{CV}$ and analyzed as both categorical and numerical variable, was the main exposure of interest. HoK and HerK were also evaluated for association with the outcome of interest.

\section{Statistical Analysis}

Quantitative variables were reported as mean and standard deviation or median and interquartile range (IQR) as appropriate. Categorical variables were described using frequencies and percentages. Normality of distribution for continuous variables was evaluated by inspecting Q-Q plots and histograms.
The association between $\left[\mathrm{K}^{+}\right]$variability and $\left[\mathrm{K}^{+}\right]$disorders with AKI was explored using a Cox regression hazard model. To account for multiple in-hospital admissions from the same patient, we used a Cox proportional hazards mixed effect "frailty" regression model, which incorporates a random intercept per patient. Survival time was defined as the time from the end of the 10-day window after in-hospital admission to development of AKI, end of the hospital stay (hospital discharge or death), or end of follow-up (30 days after the start of time at risk). All alive patients were censored at the time of hospital discharge or at the end of follow-up (Fig. 2). Hazard ratios with $95 \%$ confidence intervals were reported for all survival analyses. The covariates included in multivariable regression analyses were: age, sex, comorbidities, $\left[\mathrm{K}^{+}\right]$value at hospital admission, and eGFR value at hospital admission.

To determine whether CKD modifies the relationship between $\left[\mathrm{K}^{+}\right]$disorders (HoK and HerK) and AKI, an interaction term for the baseline eGFR, higher or lower than $60 \mathrm{~mL} / \mathrm{min} / 1.73 \mathrm{~m}^{2}$, was entered into the model. To confirm our results, as sensitivity analysis, a subanalysis was performed only in NK patients. To evaluate the effect of number of $\left[\mathrm{K}^{+}\right]$measurements and differences in observation time between the first and last $\left[\mathrm{K}^{+}\right]$measurement on the association between $\left[\mathrm{K}^{+}\right]$variability and the outcome of interest, interaction analyses between subgroups (defined according to median values of those variables and reported as dichotomous variables) and $\left[\mathrm{K}^{+}\right]$variability were performed.

For analysis and data calculation, we used the R software (version 3.4.4, R Foundation for Statistical Computing Platform). A two-tailed $p$-value $<0.05$ was considered as statistically significant.

\section{Results}

Overall, 21,830 hospital admissions from 18,836 patients were included in our study (Fig. 1). Descriptive measurements of the study population are reported in Table 1.

Patients with higher $\left[\mathrm{K}^{+}\right]$variability were older with more comorbidities. In particular, we observed a higher prevalence in cardiovascular, genitourinary, gastrointestinal, and respiratory diseases. As expected, patients in the highest quartile of $\left[\mathrm{K}^{+}\right]$variability showed a lower 
Table 1. Baseline characteristics of the study population stratified by quartile of $\left[\mathrm{K}^{+}\right]$variability

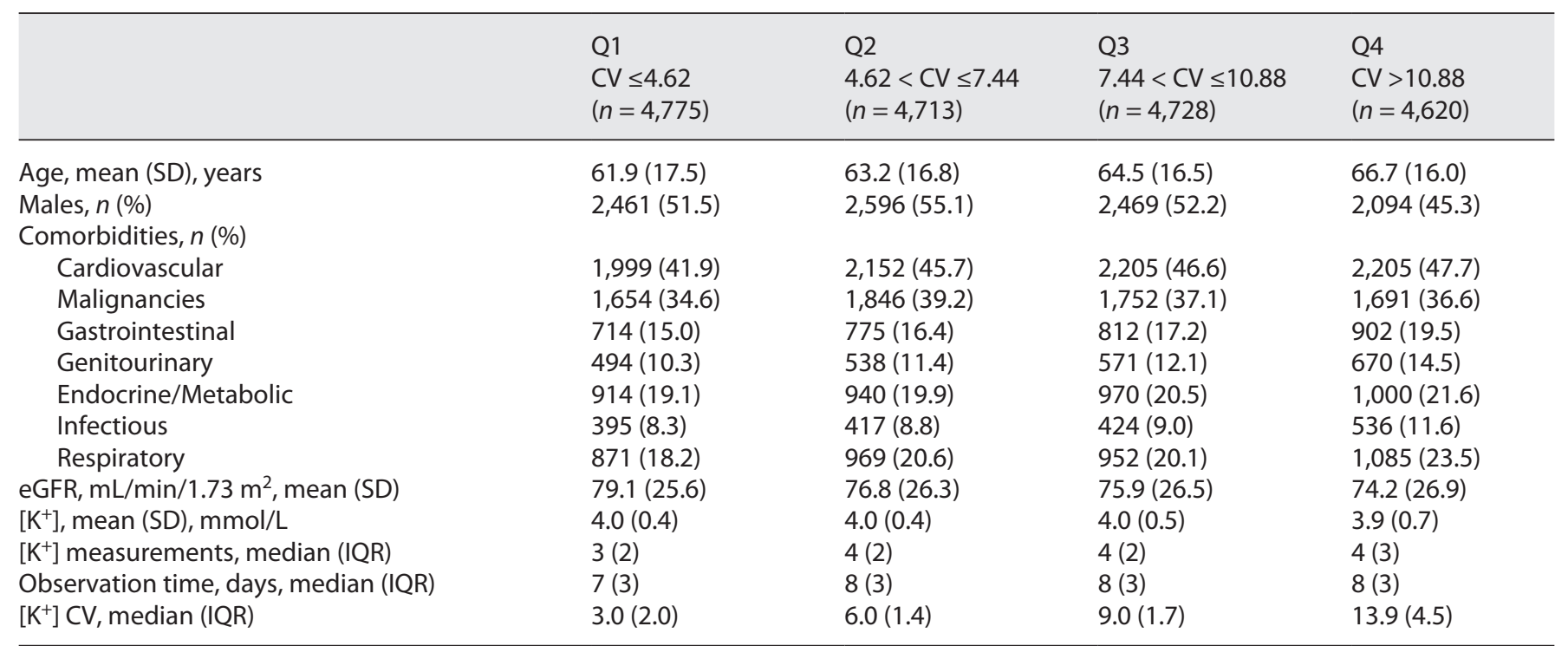

CV, coefficient of variation; SD, standard deviation.

Table 2. Association between $\left[\mathrm{K}^{+}\right]$variability and in-hospital AKI

\begin{tabular}{|c|c|c|c|c|c|c|c|}
\hline \multirow[t]{2}{*}{ CV quartile } & \multirow{2}{*}{$\begin{array}{l}\text { Events, } \\
n(\%)\end{array}$} & \multirow{2}{*}{$\begin{array}{l}\text { Person- } \\
\text { time, } \\
\text { years }\end{array}$} & \multirow{2}{*}{$\begin{array}{l}\text { Events per } \\
1,000 \text { person- } \\
\text { years }\end{array}$} & \multicolumn{2}{|l|}{ Model 1} & \multicolumn{2}{|l|}{ Model 2} \\
\hline & & & & $\mathrm{HR}(95 \% \mathrm{Cl})$ & $\begin{array}{l}p \text { value } \\
\text { for trend }\end{array}$ & $\mathrm{HR}(95 \% \mathrm{Cl})$ & $\begin{array}{l}p \text { value } \\
\text { for trend }\end{array}$ \\
\hline Q1 & $100(1.8)$ & 101.3 & 987 & 1.00 (reference) & \multirow{4}{*}{$p=0.001$} & 1.00 (reference) & \multirow{4}{*}{0.012} \\
\hline Q2 & $147(2.7)$ & 100.9 & 1,457 & $1.48(1.14,1.91) p=0.003$ & & $1.36(1.05,1.76) p=0.019$ & \\
\hline Q3 & $151(2.8)$ & 98.6 & 1,531 & $1.56(1.21,2.01) p<0.001$ & & $1.40(1.08,1.80) p=0.011$ & \\
\hline Q4 & $157(2.9)$ & 102.4 & 1,533 & $1.56(1.21,2.01) p<0.001$ & & $1.43(1.10,1.85) p=0.007$ & \\
\hline
\end{tabular}

Model 1: univariable model. Model 2: multivariable model adjusted for age, sex, comorbidities, $\left[\mathrm{K}^{+}\right]$value at hospital admission, eGFR, and value at hospital admission. $\mathrm{Cl}$, confidence interval; CV, coefficient of variation; $\mathrm{HR}$, hazard ratio.

baseline eGFR. During a median follow-up of 5 (IQR 7) days, AKI was observed in 555 hospital admissions (2.9\%), median time for AKI development 5 (IQR 7) days.

Table 2 reports the association between $\left[\mathrm{K}^{+}\right]$variability and AKI. Higher $\left[\mathrm{K}^{+}\right]$variability was independently associated with increased risk of kidney injury with a statistically significant linear trend across groups ( $p$ value $=$ 0.012 ); patients in the quartile of $\left[\mathrm{K}^{+}\right]$variability had a $43 \%$ higher risk (95\% confidence interval: 10, 85\%) compared with the first quartile. Results were materially unchanged in analyses restricted to NK patients (online suppl. Table 1; see www.karger.com/doi/10.1159/000521833 for all online suppl. material). No significant interaction was observed for the number of $\left[\mathrm{K}^{+}\right]$measurements and observation time ( $p$ values for interaction 0.44 and 0.46 , respectively) on the association between $[\mathrm{K}+]$ variability and AKI.

The prevalence of $\left[\mathrm{K}^{+}\right]$disorders was not different compared to what already reported in the literature [16]. In our study population, HerK and HoK were observed in $1,573(7.2 \%)$ and $1,475(6.8 \%)$ hospital admissions, respectively. A significantly higher incidence of AKI was documented in patients with HerK compared with NK (Table 3). However, there was no statistically significant difference between HoK and HerK ( $p$ value $=0.92$ ). No statistically significant interactions by the baseline eGFR were observed ( $p$ values for interaction 0.93 and 0.15 for HerK and HoK, respectively). 
Table 3. Association between $\left[\mathrm{K}^{+}\right]$disorders and AKI

\begin{tabular}{lllllll}
\hline Disorder & $\begin{array}{l}\text { Events, } \\
n(\%)\end{array}$ & $\begin{array}{l}\text { Person- } \\
\text { time, years }\end{array}$ & $\begin{array}{l}\text { Events per } \\
1,000 \text { person-years }\end{array}$ & Model 1 HR (95\% Cl) & Model 2 HR $(95 \% \mathrm{Cl})$ & $\mathrm{Model} \mathrm{2} \mathrm{HR} \mathrm{(95 \%} \mathrm{Cl)}$ \\
\hline NK & $429(2.3)$ & 341.0 & 1,258 & 1.00 (reference) & 1.00 (reference) & $0.75(0.55,1.04) p=0.086$ \\
HoK & $51(3.5)$ & 31.8 & 1,604 & $1.27(0.95,1.71) p=0.11$ & $1.33(0.96,1.83) p=0.086$ & $1.00($ reference $)$ \\
HerK & $75(4.8)$ & 30.4 & 2,467 & $1.98(1.54,2.54) p<0.001$ & $1.36(1.02,1.82) p=0.039$ & $1.02(0.65,1.60) p=0.92$ \\
\hline
\end{tabular}

Model 1: univariable model. Model 2: multivariable model adjusted for age, sex, comorbidities, $\left[\mathrm{K}^{+}\right]$value at hospital admission, eGFR, and value at hospital admission. $\mathrm{Cl}$, confidence interval; $\mathrm{HR}$, hazard ratio.

\section{Discussion}

Our study demonstrates a relationship between $\left[\mathrm{K}^{+}\right]$ disorders and subsequent AKI. Based on these findings, $\left[\mathrm{K}^{+}\right]$disorders are not only a consequence of kidney impairment but can also be considered a risk factor for the development of overt kidney injury. Analyzing a large cohort of hospitalized patients, we demonstrated a significant association between higher $\left[\mathrm{K}^{+}\right]$variability and $\mathrm{ab}$ normalities and kidney injury (also confirmed in NK patients).

Serum potassium $\left[\mathrm{K}^{+}\right]$imbalance is still poorly investigated for association with $\mathrm{AKI}$ and most evidence come from the intensive care unit (ICU). A recent paper from Chen et al. [17] documented a significant association between $\left[\mathrm{K}^{+}\right]$disorders and AKI in a cohort of ICU patients. To our knowledge, our study is the first to assess the relationship between $\left[\mathrm{K}^{+}\right]$disorders and AKI in a general hospitalized population. Most of the previous studies have focused on electrolyte disorders following kidney injury. Recent scientific evidence has raised new interest on electrolyte derangements and their relationship with patient outcomes $[11-14,18,19]$. Since the kidney is the main organ involved in the balance of water and electrolytes, its relationship with such disorders is not surprising.

Whether $\left[\mathrm{K}^{+}\right]$disturbances are contributors to AKI or rather simple epiphenomena is not clear and was never discussed in previous studies. The direct mechanism underlying the association between $\left[\mathrm{K}^{+}\right]$imbalance and AKI is not easy to hypothesize. Several kidney abnormalities have been related to hypokalemic status. Lower $\left[\mathrm{K}^{+}\right]$concentrations are known to induce renal structural changes, consisting of renal hypertrophy, cystic changes, and tubulointerstitial injury and fibrosis [20,21]. It is plausible that preexisting status of chronic kidney impairment, still unrevealed by $\mathrm{sCr}$ concentration, due to long-standing $\left[\mathrm{K}^{+}\right]$depletion, may predispose to AKI development. An- other possible explanation of our findings lies on the relationship between $\left[\mathrm{K}^{+}\right]$and acid-base disorders and so between HerK and metabolic acidosis [22]. It might be that HerK condition or positive $\left[\mathrm{K}^{+}\right]$fluctuations could reflect an initial or overt acid-base disorder. Accumulating evidence identifies the significant association between acidosis and kidney damage [23-26]. From a biological perspective, metabolic acidosis may reduce renal blood flow [24] and increase the release of inflammatory mediators [25], resulting in kidney injury.

However, it is worth noting that even subclinical AKI [27], yet undocumented by the rise in $\mathrm{sCr}$, could justify electrolyte abnormalities. As sparsely reported in the scientific literature, electrolyte derangements may also accompany or precede kidney damage [11, 12, 14], serving as useful serological marker of renal impairment. Previous studies have already revealed the relationship between AKI and specific electrolyte disorders including hypernatremia, hyponatremia, hyperchloremia, and hypomagnesemia [11-14, 28]. Recently, Chen et al. [12] established and validated a new risk scoring system involving several serum electrolyte disorders with a good performance on AKI prediction. Since sCr is a suboptimal marker of kidney injury and kidney research still struggles seeking the "optimal" biomarker $[29,30]$, electrolyte imbalance could play an important role on this issue improving AKI diagnosis and timely medical intervention. Embracing this concept, $\left[\mathrm{K}^{+}\right]$disorders could represent a marker of patient instability, of the severity of the underlying diseases $[9,10]$ as well as the need for greater use of medications that increase the risk of kidney injury. From this perspective, monitoring $\left[\mathrm{K}^{+}\right]$variability and disorders might represent a useful serological marker that accompanies or anticipates kidney injury.

With our paper, we propose a new point of view. Surely, $\left[\mathrm{K}^{+}\right]$disorders commonly follow AKI, but they may also precede overt kidney injury. Higher $\left[\mathrm{K}^{+}\right]$variability, which may suggest possible subsequent renal impair- 
ment, should warrant medical attention in order to pursue an early diagnosis of kidney damage and consequently establish timely therapy.

Our study has several strengths. It is the first to comprehensively analyze the relationship between $\left[\mathrm{K}^{+}\right]$disorders and subsequent AKI development in a general cohort of hospitalized patients. Furthermore, the large sample size, the robustness of results to sensitivity analyses, and a creatinine-based model for AKI definition provide strength to our findings. Moreover, using a 10-day window since in-hospital admission with stable creatinine gave us the opportunity to exclude AKI during the first days, thus reducing the risk of reverse causation by attributing an AKI event already in development at admission to our exposure of interest. Finally, the inclusion of patients from medical and surgical wards as well as intensive and non-ICUs provide more generalizability to our results. However, our study also has limitations, including the retrospective design, the lack of information on medications used during hospital stay, and the use of ICD-9$\mathrm{CM}$ codes for comorbidities definition.

In conclusion, potassium abnormalities including fluctuations even within the normal range are associated with development of AKI. Future longitudinal studies with prospective design are needed to provide more insights in such interesting topic.

\section{Statement of Ethics}

This study waived the requirement for written informed consent due to the retrospective nature of this study. The study proto$\mathrm{col}$ and the waiver of consent were approved by Institutional Re- view Board of Fondazione Policlinico Universitario A. Gemelli IRCCS (approval reference number: 34,327/18 ID 2210) and conducted in accordance with the ethical principles of the Declaration of Helsinki.

\section{Conflict of Interest Statement}

P.M.F. received consultant fees and grant support from Allena Pharmaceuticals, Alnylam, AstraZeneca, BioHealth Italia, Vifor Fresenius, and royalties as an author for UpToDate. P.M.F. is a member of the European Reference Network for Rare Kidney Diseases (ERKNet) - project ID no 739532. All the other authors report no disclosures.

\section{Funding Sources}

This study was not funded.

\section{Author Contributions}

G.L., P.M.F., and G.G. contributed to the research idea and study design. G.L. contributed to data acquisition. G.G., P.M.F., and G.L. contributed to data analysis/interpretation. P.M.F. and G.L. contributed to statistical analysis. G.L. drafted the paper. G.G. and P.M.F. contributed to supervision. Each author contributed important intellectual content during manuscript drafting for the overall work.

\section{Data Availability Statement}

The data that support the findings of this study are available from the corresponding author upon reasonable request.

\section{References}

1 Bellomo R, Kellum JA, Ronco C. Acute kidney injury. Lancet. 2012 Aug;380(9843):75666.

2 Lombardi G, Gambaro G, Pertica N, Naticchia A, Bargagli M, Ferraro PM. Seasonality of acute kidney injury in a tertiary hospital academic center: an Observational Cohort Study. Environ Health. 2021 Jan;20(1):8.

3 Thakar CV, Christianson A, Freyberg R, Almenoff $\mathrm{P}$, Render ML. Incidence and outcomes of acute kidney injury in intensive care units: a Veterans Administration Study. Crit Care Med. 2009 Sep;37(9):2552-8.

4 Zeng X, McMahon GM, Brunelli SM, Bates DW, Waikar SS. Incidence, outcomes, and comparisons across definitions of AKI in hospitalized individuals. Clin J Am Soc Nephrol. 2014 Jan;9(1):12-20.
5 Wang HE, Muntner P, Chertow GM, Warnock DG. Acute kidney injury and mortality in hospitalized patients. Am J Nephrol. 2012; 35(4):349-55.

6 Lafrance JP, Miller DR. Acute kidney injury associates with increased long-term mortality. J Am Soc Nephrol. 2010 Feb;21(2):345-52.

7 Kurzhagen JT, Dellepiane S, Cantaluppi V, Rabb H. AKI: an increasingly recognized risk factor for CKD development and progression. J Nephrol. 2020 Dec;33(6):1171-87.

8 Chertow GM, Burdick E, Honour M, Bonventre JV, Bates DW. Acute kidney injury, mortality, length of stay, and costs in hospitalized patients. J Am Soc Nephrol. 2005 Nov; 16(11): 3365-70.
9 Lameire N, Van Biesen W, Vanholder R. Electrolyte disturbances and acute kidney injury in patients with cancer. Semin Nephrol. 2010 Nov;30(6):534-47.

10 Jung SY, Kim H, Park S, Jhee JH, Yun H-R, $\mathrm{Kim} \mathrm{H}$, et al. Electrolyte and mineral disturbances in septic acute kidney injury patients undergoing continuous renal replacement therapy. Medicine. 2016 Sep;95(36):e4542.

11 Lombardi G, Ferraro PM, Naticchia A, Gambaro $G$. Serum sodium variability and acute kidney injury: a Retrospective Observational Cohort Study on a Hospitalized Population. Intern Emerg Med. 2020 Aug;16(3):617-24.

12 Chen X, Xu J, Li Y, Xu X, Shen B, Zou Z, et al Risk scoring systems including electrolyte disorders for predicting the incidence of acute kidney injury in hospitalized patients. Clin Epidemiol. 2021;13:383-96.
Serum Potassium Disorders Predict Subsequent Kidney Injury 
$13 \mathrm{Hu}$ J, Wang Y, Geng X, Chen R, Xu X, Zhang $\mathrm{X}$, et al. Metabolic acidosis as a risk factor for the development of acute kidney injury and hospital mortality. Exp Ther Med. 2017 May; 13(5):2362-74.

14 Lombardi G, Ferraro PM, Bargagli M, Naticchia A, D'Alonzo S, Gambaro G. Hyperchloremia and acute kidney injury: a Retrospective Observational Cohort Study on a general mixed medical-surgical not ICU-hospitalized population. Intern Emerg Med. 2019 Aug; 15(2):273-280

15 Waikar SS, Bonventre JV. Creatinine kinetics and the definition of acute kidney injury. J Am Soc Nephrol. 2009 Mar;20(3):672-9.

16 Eliacik E, Yildirim T, Sahin U, Kizilarslanoglu C, Tapan U, Aybal-Kutlugun A, et al. Potassium abnormalities in current clinical practice: frequency, causes, severity and management. Med Princ Pract. 2015;24(3):271-5.

17 Chen DN, Du J, Xie Y, Li M, Wang RL, Tian R. Relationship between early serum sodium and potassium levels and AKI severity and prognosis in oliguric AKI patients. Int Urol Nephrol. 2021 Jun;53(6):1171-87.
18 Lombardi G, Ferraro PM, Calvaruso L, Naticchia A, D'Alonzo S, Gambaro G. Sodium fluctuations and mortality in a general hospitalized population. Kidney Blood Press Res. 2019;44(4):604-14.

19 Lombardi G, Gambaro G, Ferraro PM. Serum potassium variability is associated with increased mortality in a large cohort of hospitalized patients. Nephrol Dial Transplant. 2021 Jul;gfab211

20 Muehrcke RC, Rosen S. Hypokalemic nephropathy in rat and man: a Light and Electron Microscpic Study. Lab Invest. 1964 Nov; 13:1359-73.

21 Riemenschneider T, Bohle A. Morphologic aspects of low-potassium and low-sodium nephropathy. Clin Nephrol. 1983 Jun;19(6): 271-9.

22 Harris AN, Grimm PR, Lee HW, Delpire E, Fang L, Verlander JW, et al. Mechanism of hyperkalemia-induced metabolic acidosis. J Am Soc Nephrol. 2018 May;29(5):1411-25.

23 Chen W, Abramowitz MK. Metabolic acidosis and the progression of chronic kidney disease. BMC Nephrol. 2014 Apr; 15:55.

24 Chowdhury AH, Cox EF, Francis ST, Lobo DN. A Randomized, Controlled, DoubleBlind Crossover Study on the effects of 2-L infusions of $0.9 \%$ saline and plasma-lyte 148 on renal blood flow velocity and renal cortical tissue perfusion in healthy volunteers. Ann Surg. 2012 Jul;256(1):18-24.
25 Peppicelli S, Bianchini F, Contena C, Tombaccini $\mathrm{D}$, Calorini $\mathrm{L}$. Acidic $\mathrm{pH}$ via NF- $\kappa \mathrm{B}$ favours VEGF-C expression in human melanoma cells. Clin Exp Metastasis. 2013 Dec; 30(8):957-67.

26 Magalhães PA, de Brito TS, Freire RS, da Silva MT, dos Santos AA, Vale ML, et al. Metabolic acidosis aggravates experimental acute kidney injury. Life Sci. 2016 Feb;146:58-65.

27 Ronco C, Kellum JA, Haase M. Subclinical AKI is still AKI. Crit Care. 2012 Jun;16(3): 313.

28 Chintala V, Prabhu VM, Boyanagari M, Bhat AN. Role of hypomagnesaemia in acute kidney injury. J Clin Diagn Res. 2018;12(3).

29 Waikar SS, Betensky RA, Bonventre JV. Creatinine as the gold standard for Kidney Injury Biomarker Studies? Nephrol Dial Transplant. 2009 Nov;24(11):3263-5.

30 Adiyanti SS, Loho T. Acute kidney injury (AKI) biomarker. Acta Med Indones. 2012 Jul;44(3):246-55. 